\title{
Pneumothorax after Endobronchial Valve Treatment: No Drain, No Gain?
}

\author{
Samuel V. Kemp ${ }^{a}$ Zaid Zoumot $^{\text {b,c }}$ Ravi Mahadevad Pallav L. Shah ${ }^{b, c, e}$ \\ ${ }^{a}$ Sherwood Forest Hospitals NHS Foundation Trust, Sutton-in-Ashfield, ${ }^{\mathrm{b}}$ The NIHR Respiratory Biomedical Research \\ Unit at Royal Brompton and Harefield NHS Foundation Trust and Imperial College, ${ }^{\mathrm{C}}$ The National Heart and Lung \\ Institute, Imperial College, London, and d Cambridge COPD Centre, Addenbrookes Hospital, Cambridge, and \\ e Chelsea and Westminster Hospital, London, UK
}

The only cure for patients with COPD/emphysema is lung transplantation. However, with the strict eligibility criteria and an inadequate supply of donor organs, this is not a realistic option for many. A variety of surgical procedures for the palliation of symptoms in lung hyperinflation due to emphysema have been attempted over many years, but little success was seen until the advent of lung volume reduction surgery (LVRS). LVRS was first reported in 1957 [1], but was not widely adopted until Joel Cooper perfected the technique of stapled resection in the mid-1990s and reported his results [2, 3].

However, the excessive early mortality observed in the high-risk patient group in the NETT (National Emphysema Treatment Trial) study [4] has led to a dramatic decrease in procedures. Prolonged hospitalisation for a variety of reasons following surgery has also contributed to this reduction.

Despite this, the potential significant benefits of lung volume reduction in selected groups with upper lobe-predominant emphysema and low baseline exercise tolerance are well recognised and can far outstrip those of pharmacological therapies. This has led to a significant investment in and development of endobronchial techniques to reduce hyperinflation. Bronchoscopic lung volume reduction is a rapidly expanding field in interven- tional pulmonology, with a number of devices now either in clinical trials or available for commercial use. These include unidirectional airway valves, endobronchial coils, sealant and steam therapy [5-15]. Endobronchial valves (EBVs) were designed to achieve volume reduction by inducing lobar atelectasis. They are the most-studied devices for bronchoscopic lung volume reduction. Largescale, randomised trials have been conducted to demonstrate their safety and efficacy [5-7]; the safety has been found to be good but, thus far, the efficacy has been modest. Improved patient selection (those patients with a low likelihood of collateral ventilation and heterogeneous disease) results in better clinical outcomes [16]. In this issue of Respiration, Gompelmann et al. [17] discuss the most commonly occurring and clinically significant major adverse event following EBV implantation, namely pneumothorax, and give us much food for thought. PostEBV pneumothoraces occur when anatomical changes in the treated lobe facilitate the expansion of the ipsilateral non-treated lobe, resulting in either ruptured pleural blebs or bullae, or parenchymal tears. In this context, the presence of significant paraseptal emphysema in the ipsilateral non-treated lobe or often unanticipated pleural adhesions can be a major concern.

\section{KARGER}

E-Mail karger@karger.com

www.karger.com/res
C 2014 S. Karger AG, Basel

0025-7931/14/0876-0452\$39.50/0
Pallav L. Shah

Royal Brompton Hospital

Sydney Street

London SW3 6NP (UK)

E-Mail pallav.shah@imperial.ac.uk 
The authors retrospectively analysed 3 trials using the Zephyr EBV (PulmonX Inc., Redwood, Calif., USA) [5, 6, 18]. The trials shared uniformity in terms of treatment approach and procedural objectives (unilateral complete lobar exclusion by placing valves to occlude all segments of a target treatment lobe). The total number of patients treated with EBVs in the 3 trials was 421, 26 of whom developed a pneumothorax at some point during the 1st year of follow-up, 25 of which were deemed to be directly related to valve implantation. Each patient had one lobe treated, with all lobes except the right middle lobe being represented. Pneumothorax was more common following left lower lobe treatment $(10.3 \%)$. This is a much rarer target, and it would be interesting to see the proportion of patients who had left lower lobe treatment who developed pneumothorax (is this in fact a very high-risk group that we should avoid treating?).

The analysis of the patients who developed a post-procedure pneumothorax demonstrated a greater degree of volume loss in the treated lobe on the follow-up CT scans than those without pneumothorax, and this was associated with improvements in airflow obstruction (mean $\mathrm{FEV}_{1}$ change $15 \pm 15 \%$ ), residual volume (mean change $-10 \pm 14 \%)$ and St. George's Respiratory Questionnaire score ( $-7 \pm 12$ points). The authors concluded that the development of pneumothorax predicts a good clinical response to EBV treatment, and that 'the benefits of therapy must be factored in when accounting for the shorter term risk of an increased rate of pneumothorax' [17].

Whilst the overall rate of pneumothorax from the studies reviewed by Gompelmann et al. [17] was 6.2\%, with the now much better appreciation of the role of collateral ventilation in patient selection, this rate is likely to be an underestimate of that seen in clinical practice. Collateral ventilation (the ventilation of distal airway structures via passages or channels that bypass the normal airways) occurs at the bronchiolar and alveolar levels [1922] and therefore has the potential to overcome the effect of unidirectional airflow through EBVs sited in major airways and thus to inhibit conformational changes that may result in pneumothorax. The importance of collateral ventilation to the outcome of EBV treatment was not fully appreciated in the enrolment phase of the VENT (Endobronchial Valve for Emphysema Palliation Trial) study. Lack of fissure integrity can be used as a surrogate predictor for collateral ventilation, and an analysis of the whole VENT dataset demonstrated that $67 \%$ of those in the treatment arm whose CT scans could be evaluated had incomplete interlobar fissures adjacent to the treated lobe. With better patient selection, the pneumothorax

Pneumothorax after Endobronchial Valve Treatment: No Drain, No Gain? rate is likely to be closer to that observed for left upper lobe treatment (i.e. about 29\%) [23]. Data from the BeLieVer HiFi trial in the UK [24] (ISRCTN04761234), which has now completed recruitment and is expected to report results in the near future, may give a better indication of the true rate of pneumothorax, as these patients were selected on the basis of fissural integrity on CT, and whilst not part of the decision-to-treat algorithm, all had CHARTIS pulmonary assessment measures performed prior to valve implantation. Correct technical placement of the valves also needs to be factored, as in the VENT studies, $46.9 \%$ of procedures (US arm 85/194 and European arm 58/111) did not achieve complete lobar exclusion due to inadequate valve placement $[5,6]$. There were incidences of pneumothorax in patients without a complete fissure (7/25 in the European cohort) [7], but the overwhelming majority of pneumothorax cases were in patients without markers of collateral ventilation on CT in whom complete lobar exclusion had been achieved.

Is EBV treatment therefore less safe than the literature suggests? Whilst pneumothorax can be seen as a 'good' complication (if such a thing can ever exist), a complication rate of $30 \%$ is a very different beast to one of $6.2 \%$. Although the pneumothorax rate is higher with optimally assessed patients, this rise in incidence has brought with it a greater awareness of the problem. Post-procedure admission is now fairly routine practice, with daycase procedures falling out of favour. In the 3 trials analysed, no patients died as a result of their post-EBV pneumothorax, which is very reassuring both for patients and treating physicians. However, there have been reports of deaths resulting from pneumothoraces occurring after the patient has been discharged from hospital, and this strengthens the case for a short period of post-admission treatment. One cannot keep these patients in hospital indefinitely, and $72 \mathrm{~h}$ seems a sensible compromise. The median time to the development of pneumothorax in the reviewed trials was 2 days [17], and therefore this policy should result in a majority of post-EBV pneumothoraces occurring in the relative safety of the hospital environment, allowing for rapid detection and intervention.

In this issue of Respiration, Valipour et al. [25] offer a timely and much needed expert opinion on managing pneumothorax following EBV treatment. This is very much based on their personal clinical experience, as the evidence base remains very limited and retrospective. However, the worldwide uptake of EBV treatment is fast on the rise and is, somewhat worryingly, expanding beyond the remit of specialised centres. Advice to perform a chest X-ray 4 and $24 \mathrm{~h}$ after treatment is logical, as is a 
period of observation in hospital. The proposed management algorithm provides a systematic approach to the treatment of pneumothorax complicating valve therapy, with clear guidance on when to resort to chest tube drainage, when and how many valves to remove and when to refer for surgical intervention. In our experience, a more patient-focused approach to the treatment of persistent air leaks with drainage and suction can also be successfully avoided with valve removal or surgery despite the duration of air leaks of up to 14 days. This demonstrates the very real need for further research specifically looking at the management of pneumothorax in this patient population.

The risk of delayed pneumothorax in a population with little respiratory and functional reserve has potentially life-threatening consequences, so consideration should be given to the potential impact of a pneumothorax on an individual basis. Informed counselling of patients as to risks and benefits and providing them with information sheets with clear instruction on symptoms to watch out for, when to access emergency services (and their contact details) as well as medical information for the benefit of first responders is strongly recommended. Establishing a link with the local hospital should be encouraged. Decisions on the timing and extent of valve removal and surgery are complex. There is a lack of knowledge about the role, function and complications of EBVs outside of the centres where the procedures are conducted, so, in the event of a significant pneumothorax, early transfer to the treating centre with expertise in the management of post-EBV pneumothorax as soon as the patient is stable is advocated.

Bronchoscopic lung volume reduction techniques are all designed to achieve similar results to LVRS without the requirement for major surgery and with reduced morbidity and mortality. When considering the major complications associated with these bronchoscopic techniques (i.e. pneumothorax, bleeding and pneumonia), one should not lose sight of the significant morbidity associated with LVRS, with nearly one third of patients requiring at least a month in hospital, high incidences of prolonged air leaks, the need for mechanical ventilation and, in some cases, further surgery $[4,26]$. Mortality is generally quoted at between 4 and $5 \%$ in line with earlier studies $[4,26]$. The surge of interest in endobronchial treatments for emphysema has resulted in increased numbers of patients being assessed in greater detail for volume reduction therapies. The improvements in patient selection, collaborative working and advances in minimally invasive surgery are likely to account for data from the Royal Bromp-

ton Hospital suggesting a $0 \%$ mortality rate for unilateral LVRS in recent years [27].

To this end, one has to consider whether pneumothorax is a true complication at all, or rather an expected event in a proportion of patients (much like an ileus following abdominal instrumentation). It is ironic that patients undergoing LVRS at an expert centre will all end up with at least one intercostal drain following their surgery, with $40 \%$ of patients requiring prolonged chest tube drainage (an air leak of greater than 7 days) and almost $5 \%$ requiring surgical re-exploration [28].

Experience is still being accumulated in the best way to manage post-EBV pneumothoraces. Collaboration and the exchange of information among those providing EBV treatments in the clinical setting and the development of clinical databases are to be strongly encouraged. This will allow the development of robust algorithms for the management of post-EBV pneumothorax, as there are currently a number of unanswered questions. Who of those without collateral ventilation is at greatest risk of pneumothorax? Who should go straight for surgical repair? How long is too long to leave the intercostal tube in place before considering valve removal or surgery? How many valves should be removed? And, when should valves be re-implanted if removed at the time of pneumothorax? And so on...

In addition, the data presented by Gompelmann et al. [17] demonstrate that a pneumothorax does not universally predict improvements in lung function, and different phenotypes of pneumothorax may become apparent as more data are gathered (e.g. parenchymal tear vs. ruptured pleural bleb or bulla).

References

Respiration 2014;87:452-455 DOI: $10.1159 / 000360643$
-1 Brantigan OC, Mueller E: Surgical treatment of pulmonary emphysema. Am Surg 1957;23: 789-804.

- 2 Cooper JD, Trulock EP, Triantafillou AN, et al: Bilateral pneumectomy (volume reduction) for chronic obstructive pulmonary disease. J Thorac Cardiovasc Surg 1995; 109:106116.

-3 Cooper JD, Patterson GA, Sundaresan RS, et al: Results of 150 consecutive bilateral lung volume reduction procedures in patients with severe emphysema. J Thorac Cardiovasc Surg 1996;112:1319-1329.

-4 Fishman A, Martinez F, Naunheim K, Piantadosi S, Wise R, Ries A, Weinmann G, Wood DE; National Emphysema Treatment Trial Research Group: A randomized trial comparing lung-volume-reduction surgery with medical therapy for severe emphysema. N Engl J Med 2003;348:2059-2073. 
5 Sciurba FC, Ernst A, Herth FJF, Strange C, Criner GJ, Marquette $\mathrm{CH}$, et al: A randomized study of endobronchial valves for advanced emphysema. N Engl J Med 2010;363:12331244.

-6 Herth FJF, Noppen M, Valipour A, Leroy S, Vergnon J-M, Ficker JH, et al: Efficacy predictors of lung volume reduction with Zephyr valves in a European cohort. Eur Respir J 2012;39:1334-1342.

7 Ninane V, Geltner C, Bezzi M, Foccoli P, Gottlieb J, Welte T, Seijo L, Zulueta JJ, Munavvar M, Rosell A, Lopez M, Jones PW, Coxson HO, Springmeyer SC, Gonzalez X: Multicentre European study for the treatment of advanced emphysema with bronchial valves. Eur Respir J 2012;39:1319-1325.

8 Hopkinson NS, Kemp SV, Toma TP, Hansell DM, Geddes DM, Shah PL, et al: Atelectasis and survival after bronchoscopic lung volume reduction for COPD. Eur Respir J 2011;37: 1346-1351.

-9 Kramer MR, Refaely Y, Maimon N, Rosengarten D, Fruchter O: Bilateral endoscopic sealant lung volume reduction therapy for advanced emphysema. Chest 2012;142:1111-1117.

10 Snell G, Herth FJ, Hopkins P, Baker KM, Witt C, Gotfried MH, et al: Bronchoscopic thermal vapour ablation therapy in the management of heterogeneous emphysema. Eur Respir J 2012:39:1326-1333.

11 Magnussen H, Kramer MR, Kirsten AM Marquette C, Valipour A, Stanzel F, et al: Effect of fissure integrity on lung volume reduction using a polymer sealant in advanced emphysema. Thorax 2012;67:302-308.

-12 Gompelmann D, Heussel CP, Eberhardt R, Snell G, Hopkins P, Baker K, et al: Efficacy of bronchoscopic thermal vapour ablation and lobar fissure completeness in patients with heterogeneous emphysema. Respiration 2012;83:400-406.
13 Shah PL, Slebos DJ, Cardoso PFG, et al: Bronchoscopic lung-volume reduction with $\mathrm{Ex}$ hale airway stents for emphysema (EASE trial): randomised, sham-controlled, multicentre trial. Lancet 2011;378:997-1005.

14 Slebos D-J, Klooster K, Ernst A, Herth FJF, Kerstjens HAM: Bronchoscopic lung volume reduction coil treatment of patients with severe heterogeneous emphysema. Chest 2012; 142:574-582.

15 Shah PL, Zoumot Z, Singh S, Bicknell SR, Ross ET, Quiring J, et al: Endobronchial coils for the treatment of severe emphysema with hyperinflation (RESET): a randomised controlled trial. Lancet Respir Med 2013;1:233240.

16 Shah PL, Herth FJ: Current status of bronchoscopic lung volume reduction with endobronchial valves. Thorax 2014;69:280-286.

17 Gompelmann D, Herth FJF, Slebos DJ, Valipour A, Ernst A, Criner GJ, Eberhardt R: Pneumothorax following endobronchial valve therapy and its impact on clinical outcomes in severe emphysema. Respiration 2014;87:485-491.

18 Herth FJ, Eberhardt R, Gompelmann D, Ficker JH, Wagner M, Ek L, Schmidt B, Slebos DJ: Radiological and clinical outcomes of using Chartis ${ }^{\mathrm{TM}}$ to plan endobronchial valve treatment. Eur Respir J 2013;41:302-308.

$>19$ Andersen JB, Jespersen W: Demonstration of intersegmental respiratory bronchioles in normal human lungs. Eur J Respir Dis 1980; 61:337-341.

20 Kohn HN: Zur Histologie des indurirenden fibrinosen Pneumonia. Munch Med Woch 1893;40:42-45.
21 Lambert MW: Accessory bronchiolealveolar communications. J Pathol Bacteriol 1955;70: 311-314.

- 22 Van Allen CM, Lindskog GE, Richter HG: Collateral respiration. Transfer of air collaterally between pulmonary lobules. J Clin Invest 1931; 10:559-590.

-23 Sterman DH, Mehta AC, Wood DE, Mathur PN, McKenna RJ Jr, Ost DE, et al: A multicenter pilot study of a bronchial valve for the treatment of severe emphysema. Respiration 2010;79:222-233.

24 Davey C, Zoumot Z, Jordan S, Carr DH, Polkey MI, Shah PL, Hopkinson NS: Bronchoscopic lung volume reduction with endobronchial valves for patients with heterogeneous emphysema and intact interlobar fissures (The BeLieVeR-HIFi trial): study design and rationale. Thorax 2014, DOI: 10.1136/ thoraxjnl-2014-205127. Epub ahead of print.

25 Valipour A, Slebos D-J, de Oliveira HG, Eberhardt R, Freitag L, Criner GJ, Herth FJF: Expert statement: pneumothorax associated with endoscopic valve therapy for emphysema: potential mechanisms, treatment algorithm, and case examples. Respiration 2014;87:513-521.

26 Ciccone AM, Meyers BF, Guthrie TJ, et al: Long-term outcome of bilateral lung volume reduction in 250 consecutive patients with emphysema. J Thorac Cardiovasc Surg 2003; 125:513-525.

27 Clark S, Zoumot Z, Davey C, et al: 12 years of thoracic surgery for emphysema at The Royal Brompton Hospital. Annual Congress of the European Respiratory Society 2013 (abstract P4335).

28 Meyers BF, Sultan PK, Guthrie TJ, et al: Outcomes after unilateral lung volume reduction. Ann Thorac Surg 2008;86:204-211. 